\title{
Effects of Aegle marmelos (L.) Methanolic Leaf Extracts on Cardiovascular Parameters in Diabetic Rats
}

\author{
Ravi Babu Birudu ${ }^{1}$, Padmavathi Pamulapati ${ }^{1, ~}$, Manoharan Sathish Kumar ${ }^{2}$ \\ ${ }^{1}$ Department of Zoology \& Aquaculture, Acharya Nagarjuna University, Andhra Pradesh, India \\ ${ }^{2}$ Department of Pharmacology, Bapatla College of Pharmacy, Bapatla, Andhra Pradesh, India
}

Email address:

padmapin@yahoo.co.in (P. Pamulapati)

${ }^{*}$ Corresponding author

\section{To cite this article:}

Ravi Babu Birudu, Padmavathi Pamulapati, Manoharan Sathish Kumar. Effects of Aegle marmelos (L.) Methanolic Leaf Extracts on Cardiovascular Parameters in Diabetic Rats. Journal of Diseases and Medicinal Plants. Vol. 6, No. 4, 2020, pp. 77-81. doi: $10.11648 /$ j.jdmp.20200604.11

Received: September 15, 2020; Accepted: September 27, 2020; Published: October 7, 2020

\begin{abstract}
Aegle marmelos (L.) Correa is a widely found plant in India as well as in South Asia. For more than several centuries it is being widely used for its medicinal properties. The objective of the study was to evaluate the cardiovascular changes in alloxan induced diabetic rats treated with methanolic leaf extracts of Aegle marmelos. 5 treatment groups (namely control, diseased, low dose $(100 \mathrm{mg} / \mathrm{kg})$, medium dose $(250 \mathrm{mg} / \mathrm{kg})$ and high dose $(500 \mathrm{mg} / \mathrm{kg})$ of methanolic leaf extracts were used in the study. The cardiovasculareffects were evaluated by the determination of Very-Low-Density Lipoprotein (VLDL), Serum Sialic Acid, Glutathione Peroxidase, Serum Catalase, Ascorbic acid, Sodium, Potassium, and Chloride levels. High dose treatment group showed significant decrease in Very-Low-Density Lipoprotein (VLDL), Serum Sialic Acid, Glutathione Peroxidase, Serum Catalase, Ascorbic acid, Sodium, Potassium, and Chloride levels when compared with the diseased treatment groups. Though Low and medium dose treated animals showed insignificant decrease in these cardiovascular parameters when compared with high dose treatment group as well as diseased group. The effects of high dose treatment on cardiovascular parameters were very significant as that of control group. Through the cardiovascular parameters it is evident that the highdose of methonolic leaf extract of Aegle marmelos can be used the treatment of diabetes and its cardiovascular complications.
\end{abstract}

Keywords: Aegle marmelos, Rutaceae, Bael, Alloxan, Diabetes, Cardiovascular Parameters

\section{Introduction}

Natural products have a very special place in drug research and development. Plants as a source of therapeutically useful drugs have been proved the evidence of high economic importance. Search for new drugs from various plant sources occurs throughout the globe. In India though there are certain limitations or challenges in the resources, standardization of medicinal plants has gained significance in the recent times [1].

Aegle marmelos (L.) Correa is a widely found medicinal plant in India and South Asia. It is being commonly used for its therapeutic properties [2]. Antinociceptive activity [3], hepatoprotective activity $[4,5]$, antioxidant activity $[4,10$, 17-20], antimicrobial activity [6], antibiofilm activity [6], cytotoxic activity $[6,10]$, antifeedant activity [6], larvicidal activity [6], antiproliferative activity [7, 13, 19], cholinergic agonist activity [8], serotonergic agonist activity [8], adrenergic agonist activity [8], antifungal activity [9, 11], transcriptome gene activity [12], anticancer activity [13], antidiarrhoeal activity [14], protective effects against fructose induced hepatic insulin resistance [15], immunomodulatory activity [16], proctective effects against chronic fatigue syndrome [20], antilipidemic activity [21, 28], antihypercholestrolemic activity $[21,28]$, anti ulcer activity [22], detoxifying activity [23], diuretic activity [24], antibacterial activity [25], anti filarial activity [26], antidiabetic activity [27] has been reported in various plant extracts of the plant. Most of the phytocompunds are found be accumulated in the leaves of the plants. Therefore, the present research work was aimed at the evaluation of cardiovascular changes in diabetic rats treated with methanolic leaf extracts from Aegle marmelos. 


\section{Materials and Methods}

\subsection{Collection of Plant Material}

The leaves of Aegle marmelos (L.) were collected from Dolas Nagar, Tadepalli Mandal, Guntur District, Andhra Pradesh, India. Authentication was done by Dr. P. Satya Narayana Raju, Plant Taxonomist, Department of Botany and Microbiology, Acharya Nagarjuna University, Guntur, AP, India. The reference specimen is preserved in the Department of Botany, Acharya Nagarjuna University, Nagarjuna Nagar, Guntur.

\subsection{Preparation of Plant Extracts}

The collected leaves were washed thoroughly with water and shade dried. Methanolic leaf extracts was obtained by extracting powder with $85 \%$ ethanol by Soxhlet extraction method for $72 \mathrm{~h}$. After completion of the extraction, the excess solvent was removed by rotary evaporation. The methanolic leaf extract was used for further evaluation of biochemical changes in alloxan induced diabetes.

\subsection{Preliminary Phytochemical Analysis}

The methanolic leaf extract from Aegle marmelos (L.) was subjected to preliminary phytochemical analysis to assess the presence of various phytoconstituents; it revealed the presence of glycosides, saponins, tannins and flavonoids.

\subsection{Animals}

Normal healthy male wistar albino rats, 9-12 weeks old with an average weight of 200-250gm were procured from the Mahaveer Enterprises (CPCSEA Regd No: 146/99/CPCSEA), Bagh Amberpet, Hyderabad. They were housed in polypropylene cages and fed with a standard chow diet and water ad libitum.

The animals were acclimatized to the conditions by maintaining them at a temperature $25 \pm 2^{\circ} \mathrm{C}$ and relative humidity $55 \pm 10$ at $12 \mathrm{~h}$ each at dark and light cycle for about 7 days prior to dosing and during the commencement of experiment.

All experimental procedures involving animals were conducted in accordance with the guidelines of Committee for the Purpose of Control and Supervision on Experiments on Animals (CPCSEA) with prior approval from Institutional Animal Ethics Committee (IAEC Approval No. ANUCPS/IAEC/AM/P/26/2019) of College of Pharmaceutical Sciences, Acharya Nagarjuna University, Nagarjuna Nagar, Guntur, Andhra Pradesh, India.

\subsection{Treatment Groups}

The cardiovascular changes were evaluated using alloxan induced diabetes model. [29, 30] A total of 30 rats were used. The rats were divided into 5 groups of 6 rats each. Group 1: Vehicle treatment group; Group 2: Disease Control; Group 3: Low dose of methanolic leaf extract $(100 \mathrm{mg} / \mathrm{kg})$; Group 4: Medium dose of methanolic leaf extract $(250 \mathrm{mg} / \mathrm{kg})$ and Group 5: High dose $(500 \mathrm{mg} / \mathrm{kg})$. Plant leaf extracts were suspended in vehicle solution of $0.5 \%$ dimethyl sulfoxide [DMSO] and a dose of $1 \mathrm{ml} / \mathrm{kg}$, body weight was administered orally using an intragastric tube for 15-45 days to the respective groups.

\subsection{Chemicals}

Alloxan monohydrate was procured from Sigma Aldrich, Bangalore. All the other chemicals and solvents used in the study were of analytical grade and obtained from local suppliers.

\subsection{Acute Toxicity Studies}

The acute toxicity studies were carried out in accordance with OECD Test Guideline 423: Acute Oral Toxicity - Acute Toxic Class Method. The methanolic leaf extract of Aegle marmelos (L.) was found to be safe up to $2000 \mathrm{mg} / \mathrm{kg}$ body weight after oral administration of the test compound. 100 $\mathrm{mg} / \mathrm{kg}, 250 \mathrm{mg} / \mathrm{kg}$ and $500 \mathrm{mg} / \mathrm{kg}$ were used for further animal pharmacological study.

\subsection{Parameters Evaluated}

Diabetes was induced by the administration of alloxan monohydrate $(150 \mathrm{mg} / \mathrm{kg}$ b.w, ) with normal saline as vehicle. After $72 \mathrm{~h}$, rats with blood glucose levels more than 150 $\mathrm{mg} / \mathrm{dl}$ was selected for further biochemical evaluation. The blood glucose levels were estimated using one touch glucometer. The cardiovascular effects were evaluated by the determination of Very-Low-Density Lipoprotein (VLDL), Serum Sialic Acid, Glutathione Peroxidase, Serum Catalase, Ascorbic acid, Sodium, Potassium, and Chloride levels [31].

\subsection{Statistical Analysis}

Results of the study were presented as mean \pm standard error of the mean. The statistical significance of the groups was determined using one-way analysis of variance followed by Dunnett's test usingGraph Pad PRISM Software and $\mathrm{P}<$ 0.05 was considered as significant.

\section{Results and Discussion}

\subsection{Effects of Methanolic Leaf Extracts on Very-Low-Density Lipoprotein (VLDL) of the Treated Animals}

Higher Very-Low-Density Lipoprotein (VLDL) is an indication of disease in the heart, blood vessels, liver, kidney or intestines. It's also linked to diabetes, low thyroid activity and leukemia. There were significant changes in Very-LowDensity Lipoprotein (VLDL) among the treatment groups when compared with the diseased [32]. There were no significant changes in VLDL levels between treatment and control treatment groups. The statistical significance between the groups was found to be $\mathrm{P}<0.05$. The effects of methanolic leaf extracts on Very-Low-Density Lipoprotein (VLDL) of the treated rats are shown in Table 1. 
Table 1. Effects of Aegle marmelos (L.) methanolic leaf extracts on cardiovascular parameters in diabetic rats.

\begin{tabular}{|c|c|c|c|c|c|c|}
\hline S. No & Parameter (s) & Normal & Diseased & Low Dose & Medium Dose & High Dose \\
\hline 1 & VLDL (mg/dl) & $26.36 \pm 1.26$ & $36.08 \pm 1.87 * *$ & $31 \pm 1.73$ & $28.11 \pm 1.63$ & $26.65 \pm 0.55 * *$ \\
\hline 2 & Serum Sialic Acid (mg/\%) & $67.33 \pm 1.36$ & $84.93 \pm 1.66^{* *}$ & $75.66 \pm 1.16$ & $72.06 \pm 1.48$ & $68.91 \pm 0.88 * *$ \\
\hline 3 & Glutathione Peroxidase (mg/L) & $91.81 \pm 1.24$ & $153.61 \pm 1.38^{* *}$ & $126.91 \pm 1.01$ & $122.91 \pm 2.01$ & $91.76 \pm 0.80 * *$ \\
\hline 4 & Serum Catalase (MU/L) & $111.71 \pm 0.01$ & $126.58 \pm 1.48^{* *}$ & $124.61 \pm 1.06$ & $121.62 \pm 2.00$ & $112.23 \pm 1.34 * *$ \\
\hline 5 & Ascorbic Acid (mg/dl) & $0.5 \pm 0.14$ & $3.65 \pm 0.26^{* *}$ & $2.57 \pm 0.77$ & $1.96 \pm 0.37$ & $0.53 \pm 0.05 * *$ \\
\hline 6 & Sodium $(\mathrm{mg} / \mathrm{dl})$ & $143.48 \pm 0.31$ & $166.26 \pm 0.82 * *$ & $163.15 \pm 1.73$ & $157.88 \pm 1.44$ & $143.56 \pm 1.10^{* *}$ \\
\hline 7 & Potassium (mg/dl) & $5.5 \pm 0.23$ & $6.38 \pm 0.24 * *$ & $5.66 \pm 0.16$ & $5.55 \pm 0.38 * *$ & $5.36 \pm 0.21 * *$ \\
\hline 8 & Chloride $(\mathrm{mEq} / \mathrm{L})$ & $104.23 \pm 2.88$ & $144.68 \pm 2.69 * *$ & $138.45 \pm 1.78$ & $127.26 \pm 1.47$ & $104.35 \pm 1.39 * *$ \\
\hline
\end{tabular}

The cardiovascular parameters of diseased groups were compared with control group and treatment groups $(\mathrm{p}<0.05)$.

\subsection{Effects of Methanolic Leaf Extracts on Serum Sialic Acidand Serum Catalase Levels of the Animals}

The physiological properties of serum sialic acid and serum catalase may explain its ability to protect against the progression of diabetes. These properties make serum sialic acid and serum catalase a potential clinical biomarker or therapeutic target for a variety of disease states. Extremely significant decrease in the serum sialic acid and serum catalaselevels was observed in the highdose treated animals when compared to the diseased group animals [33]. The statistical significance between the groups was found to be $\mathrm{P}<0.05$. The effects of methanolic leaf extracts on serum sialic acid and serum catalase levels of the treated rats are shown in Table 1.

\subsection{Effects of Methanolic leaf Extracts on Glutathione and Ascorbic Acid Levels of the Animals}

The physiological properties of glutathione and ascorbic acid levels may explain its ability to protect against the progression of diabetes [34]. These properties make glutathione and ascorbic acid a potential clinical biomarker or therapeutic target for a variety of disease states. Extremely significant decrease in the glutathione and ascorbic acid levels was observed in the high dose treated animalswhen compared to the diseased group animals. The statistical significance between the groups was found to be $\mathrm{P}<0.05$. The effects of methanolic leaf extracts on glutathione and ascorbic acid levels of the treated rats are shown in Table 1.

\subsection{Effects of Methanolic Leaf Extracts on Sodium, Potassium and Chloride Levels of the Animals}

Extremely significant decrease in the sodium, potassium and chloride levels was observed in the high dose treated animals when compared to the diseased group animals.[35] The statistical significance between the groups was found to be $\mathrm{P}<0.05$. The effects of methanolic leaf extracts on sodium, potassium and chloride levelsof the treated rats are shown in Table 1.

\section{Conclusion}

Through the cardiovascular parameters it is evident that the high dose of methonolic leaf extracts from Aegle marmelos can be used the treatment of diabetes and its cardiovascular complications. The antidiabetic activity could be attributed to the presence of flavonoids in the extracts. However, there is a need for further cellular and molecular pharmacological studies to elucidate the exact mechanisms for its antidiabetic potential.

\section{Financial Support and Sponsorship}

Nil.

\section{Conflicts of Interest}

The authors declare that they have no competing interests.

\section{Acknowledgements}

Authors are thankful to Acharya Nagarjuna University, Nagarjuna Nagar, Andhra Pradesh for providing necessary laboratory conditions.

\section{References}

[1] Buenz EJ, Schnepple DJ, Bauer BA, Elkin PL, Riddle JM, Motley TJ. Techniques: bioprospecting historical herbal texts by hunting for new leads in old tomes. Trends Pharmacol Sci 2004; 25 (9): 494-8.

[2] Mujeeb F, Bajpai P, Pathak N. Phytochemical evaluation, antimicrobial activity and determination of bioactive components from leaves of Aegle marmelos. Biomed Res Int 2014; 10 (2); 1-12.

[3] Kothari S, Kushwah A, Kothari D. Involvement of opioid and monoaminergic pain pathways in Aegle marmelos induced analgesia in mice. Indian J Pharmacol 2013; 45 (4): 371-5.

[4] Rathee D, Kamboj A, Sidhu S. Augmentation of hepatoprotective potential of Aegle marmelos in combination with piperine in carbon tetrachloride model in wistar rats. Chem Cent J 2018; 12 (1): 94-9.

[5] Ibrahim NA, Mohammed MM, Aly HF, Ali SA, Al-Hady DA. Efficiency of the leaves and fruits of Aegle marmelos methanol extract (L.) Correa and their relative hepatotoxicity induced by CCL4 and identification of their active constituents by using LC/MS/MS. Toxicol Rep. 2018; 5: 1161-8. 
[6] Rejiniemon TS, Arasu MV, Duraipandiyan V, Ponmurugan K, Al-Dhabi NA, Arokiyaraj S, et al. in-vitro antimicrobial, antibiofilm, cytotoxic, antifeedant and larvicidal properties of novel quinone isolated from Aegle marmelos (Linn.) Correa. Ann Clin Microbiol Antimicrob. 2014; 13 (1): 48-57.

[7] Bhatti R, Singh J, Saxena AK, Suri N, Ishar MP. Pharmacognostic standardisation and antiproliferative activity of Aegle marmelos (L.) Correa leaves in various human cancer cell lines. Indian J Pharm Sci. 2013; 75 (6): 628-36.

[8] Kumar S, Mahaseth RK, Tiwari M, Sehgal R, Rajora P, Mathur R. Interaction of aqueous leaf extract of Aegle marmelos (L.) Corr. with cholinergic, serotonergic and adrenergic receptors: An ex vivo study. Indian J Pharmacol. 2015; 47 (1): 109-16.

[9] Balakumar S, Rajan S, Thirunalasundari T, Jeeva S. Antifungal activity of Aegle marmelos (L.) Correa (Rutaceae) leaf extract on dermatophytes. Asian Pac J Trop Biomed. 2011; 1 (4): 309-12.

[10] Mujeeb F, Khan AF, Bajpai P, Pathak N. Phytochemical study of Aegle marmelos: Chromatographic elucidation of polyphenolics and assessment of antioxidant and cytotoxic potential. Pharmacogn Mag. 2017; 13 (Suppl 4): S791.

[11] Rana BK, Singh UP, Taneja V. Antifungal activity and kinetics of inhibition by essential oil isolated from leaves of Aegle marmelos. J Ethnopharmacol. 1997; 57 (1): 29-34.

[12] Kaushik P, Kumar S. Data of de novo assembly of the leaf transcriptome in Aegle marmelos. Data Brief. 2018; 19: 700-3.

[13] Subramaniam D, Giridharan P, Murmu N, Shankaranarayanan NP, May R, Houchen CW, et al. Activation of apoptosis by 1hydroxy-5, 7-dimethoxy-2-naphthalene-carboxaldehyde, a novel compound from Aegle marmelos. Cancer Res. 2008; 68 (20): 8573-81.

[14] Brijesh S, Daswani P, Tetali P, Antia N, Birdi T. Studies on the antidiarrhoeal activity of Aegle marmelos unripe fruit: Validating its traditional usage. BMC Complement Altern Med. 2009; 9 (1): 47-55.

[15] Nair J, Velpandian T, Das US, Sharma P, Nag T, Mathur SR, Mathur R. Molecular and Metabolic Markers of Fructose Induced Hepatic Insulin Resistance in Developing and Adult Rats are Distinct and Aegle marmelos is an Effective Modulator. Sci Rep. 2018; 8 (1): 15950-9.

[16] Govinda HV, Asdaq SM. Immunomodulatory potential of methanol extract of Aegle marmelos in animals. Indian $\mathrm{J}$ Pharm Sci. 2011; 73 (2): 235-42.

[17] Reddy VP, Urooj A. Antioxidant properties and stability of Aegle marmelos leaves extracts. Food Sci Technol. 2013; 50 (1): 135-40.

[18] Nair CJ, Ahamad S, Khan W, Anjum V, Mathur R. Development and validation of high-performance thin-layer chromatography method for simultaneous determination of polyphenolic compounds in medicinal plants. Pharmacognosy Res. 2017; (Suppl 1): S67.

[19] Chockalingam V, Kadali SS, Gnanasambantham P. Antiproliferative and antioxidant activity of Aegle marmelos (Linn.) leaves in Dalton's Lymphoma Ascites transplanted mice. Indian J Pharmacol. 2012; 44 (2): 225-34.
[20] Lalremruta V, Prasanna GS. Evaluation of protective effect of Aegle marmelos Corr. in an animal model of chronic fatigue syndrome. Indian J Pharmacol. 2012; 44 (3): 351-9.

[21] Asghar N, Mushtaq Z, Arshad MU, Imran M, Ahmad RS, Hussain SM. Phytochemical composition, antilipidemic and antihypercholestrolemic perspectives of Bael leaf extracts. Lipids Health Dis. 2018; 17 (1): 68-76.

[22] Ilavarasan JR, Monideen S, Vijayalakshmi M. Antiulcer activity of Aegle marmelos Linn. Anc Sci Life. 2002; 21 (4): 256-64.

[23] Vinodhini R. Detoxifying effect of Nelumbo nucifera and Aegle marmelos on hematological parameters of Common Carp (Cyprinus carpio L.). Interdiscip Toxicol. 2010; 3 (4): 127-31.

[24] Parmar NA, Patel BR, Nariya MB. A comparative experimental study to evaluate Mutrala (diuretic) activity of Bilva Moola and Patra (Aegle marmelos Corr.). Ayu. 2014; 35 (3): 344-9.

[25] Perumal Samy R, Manikandan J, Al Qahtani M. Evaluation of aromatic plants and compounds used to fight multidrug resistant infections. Evid Based Complement Alternat Med. 2013; 15 (4): 1-17.

[26] Sharma RD, Veerpathran AR, Dakshinamoorthy G, Sahare KN, Goswami K, Reddy MV. Possible implication of oxidative stress in anti filarial effect of certain traditionally used medicinal plants in vitro against Brugia malayi microfilariae. Pharmacognosy Res. 2010; 2 (6): 350-9.

[27] Namsa ND, Tangjang S, Arya SC, Rajbonshi B, Samal PK, Mandal M. An inventory of the ethnobotanicals used as anti-diabetic by a rural community of Dhemaji district of Assam, Northeast India. J Ethnopharmacol. 2011; 138 (2): 345-50.

[28] Liaqat I, Riaz N, Saleem QU, Tahir HM, Arshad M, Arshad N Toxicological evaluation of essential oils from some plants of rutaceae family. Evid Based Complement Alternat Med. 2018; $15(2), 1-17$.

[29] Yadav JP, Saini S, Kalia AN, Dangi AS. Hypoglycemic and hypolipidemic activity of ethanolic extract of Salvadora oleoides in normal and alloxan-induced diabetic rats. Indian J Pharmacol. 2008; 40 (1): 23-27.

[30] Ponnachan PT, Paulose CS, Panikkar KR. Effect of leaf extract of Aegle marmelose in diabetic rats. Indian J Exp Biol. 1993; 31 (4): 345-7.

[31] Tiwari BK, Kumar D, Abidi AB, Rizvi SI. Efficacy of composite extract from leaves and fruits of medicinal plants used in traditional diabetic therapy against oxidative stress in alloxan-induced diabetic rats. International Scholarly Research Notices. 2014.

[32] Jelastin KS, Tresina PS, Mohan VR. Antioxidant, antihyperlipidaemic and antidiabetic activity of Eugenia floccosa Bedd leaves in alloxan induced diabetic rats. Journal of basic and clinical pharmacy. 2011 Dec; 3 (1): 235.

[33] Melo da Cunha JD, Alfredo TM, dos Santos JM, Alves Junior VV, Rabelo LA, Lima ES, Boleti AP, Carollo CA, dos Santos EL, de Picoli Souza K. Antioxidant, antihyperglycemic, and antidiabetic activity of Apis mellifera bee tea. PloS one. 2018 Jun 5; 13 (6): e0197071. 
[34] Goji AD, Muhammed KA, Tende JA, Aisha I. Effects of CoAdministration of Lycopene and/or Zinc on Serum Electrolyte in Alloxan-Induced Diabetic Wistar Rat. Journal of Medical Biomedical and Applied Sciences. 2018 Jun 7; 6 (6): 57-61. 